\title{
Lupus Anticoagulant, Antiphospholipid Antibodies and Migraine
}

\author{
M.J. Hogan, D.G. Brunet, P.M. Ford and D. Lillicrap
}

\begin{abstract}
The records of fifteen patients referred for neurological assessment and found to have lupus anticoagulant or elevated anticardiolipin antibodies were reviewed. The mean age for females in the group was 29.4 years and for males was 35. A diagnosis of migraine, either as an acute or chronic problem, was made in $10(66 \%)$ of these patients. Seven of the 15 patients had ischemic stroke and two patients had other thrombotic complications associated with lupus anticoagulant. Three of the nine female patients with migraine had histories of spontaneous abortions. All migraine patients experienced transient or more prolonged neurological deficits with their headaches. An association between lupus anticoagulant and migraine can only be suggested. Data on the incidence of migraine in patients with lupus anticoagulant in the general medical population does not exist. Furthermore the prevalence of lupus anticoagulant in migraine sufferers is unknown. Therefore further studies are required to investigate this possible association.
\end{abstract}

RÉSUMÉ: Anticoagulant lupique, anticorps antiphospholipide et migraine Les dossiers de quinze patients référés pour évaluation neurologique, chez qui on avait mis en évidence un anticoagulant lupique ou un taux élevé d'anticorps anticardiolipine, ont été revisés. Dans ce groupe de patients, l'âge moyen des femmes était de 29.4 ans et celui des hommes de 35 ans. Un diagnostic de migraine a été posé chez $10(66 \%)$ de ces patients, tant chez ceux dont le problème était aigu que chez ceux chez qui il était chronique. Sept des quinze patients avaient fait un accident cérébro-vasculaire d'origine ischémique et deux patients présentaient d'autres complications thrombotiques associées à l'anticoagulant lupique. Trois des neuf patientes migraineuses avaient une histoire de fausses couches. Tous les patients migraineux avaient présenté des déficits neurologiques transitoires ou prolongés accompagnant leurs céphalées. Une association entre l'anticoagulant lupique et la migraine ne peut qu'être suggérée. Il n'existe pas de données sur l'incidence de la migraine chez les patients qui ont un anticoagulant lupique dans la population générale venant à l'attention médicale. De plus, la prévalence de l'anticoagulant lupique chez les patients souffrant de migraines est inconnue. Par conséquent, il est nécessaire de procéder à des études supplémentaires pour investiguer la possibilité qu'une telle association existe.

Can. J. Neurol.Sci. 1988; 15:420-425

Lupus anticoagulant (LAC) is an IgG or less frequently an IgM antibody that belongs to a group of antibodies directed against phospholipid. LAC was first identified in 1952 in two patients with systemic lupus erythematosus (SLE) who were reported to have a bleeding tendency. ${ }^{1}$ Espinoza and Hartmann ${ }^{2}$ in a recent review reported a prevalence of LAC of approximately $10 \%$ in SLE but a wide range (6\% to $71 \%$ ) has been reported elsewhere. ${ }^{3}$ LAC has also been identified in patients who do not have other features of SLE. Schleider et al ${ }^{4}$ and Gastineau et al 5 reported on 58 and 219 identified cases of LAC respectively and both groups found that approximately half of the patients studied did not have SLE.

Although the LAC has an in vitro anticoagulant effect (by neutralizing the procoagulant phospholipids in the assay system ${ }^{3)}$ most patients with these antibodies have a tendency to develop thrombotic complications. ${ }^{1,3,6}$ Bleeding is an unusual complication and when it occurs there is usually some other defect in the clotting mechanism. $13,5,7$ The incidence of throm- bosis in SLE patients with LAC has been reported to range from $23 \%$ to $58 \%{ }^{7,8,9}$ The incidence of thrombosis in SLE patients without LAC is approximately $15 \%$. 9,10 Patients with LAC who do not have SLE have a similar risk for thrombotic complications as patients with both LAC and SLE. 5

The reason for the thrombotic tendency in patients with LAC has not been determined. There is a strong, but not absolute correlation, between LAC and elevated antibodies to the phospholipid cardiolipin. " Elevated anticardiolipin antibody (ACA) levels have been shown to be associated with thrombotic complications. ${ }^{11,12}$ Among the theories proposed for the thrombotic pathogenesis of LAC and antiphospholipid antibodies is the inhibition of $\mathrm{PGI}_{2}$ production by interaction of the antibodies with phospholipid within endothelial cell membranes. ${ }^{13}$ $\mathrm{PGI}_{2}$ is a vasodilator and an inhibitor of platelet aggregation produced by endothelial cells. It has also been suggested that platelets may be predisposed to aggregation secondary to membrane bound antiphospholipid antibody. 20

From the Departments of Medicine, (Drs. Hogan, Brunet, Ford, Lillicrap) and Pathology (Drs. Ford and Lillicrap) Queen's University, Kingston

Received January 12, 1988. Accepted in final form June 30, 1988

Presented in part at the 23rd Canadian Congress of Neurological Sciences, Quebec, June 1988. Dr. Hogan was awarded the Francis McNaughton Memorial Prize for the best paper submitted by a junior member of the Canadian Neurological Society

Reprint requests to: Dr. D.G. Brunet, c/o EEG Department, Kingston General Hospital, Kingston, Ontario, Canada K7L 2V7 
Central nervous system complications are recognized in LAC patients. These are principally due to cerebrovascular thrombotic events which have been reported to occur in $3 \%$ to $18 \%$ of patients with LAC. 5,7,14 There are several reports of LAC in young patients presenting with cerebrovascular ischemia with or without other conditions predisposing to stroke. ${ }^{15,16,17,18,19}$ Levine and Welch ${ }^{20}$ have recently presented a review of 32 reported cases of lupus anticoagulant associated with cerebrovascular ischemia. Twenty-five patients did not have SLE but 15 of these patients were reported to have other definite stroke risk factors.

Migraine associated with LAC was first reported by Brandt and Lessell21 in 2 of 11 patients with SLE and migraine.

Recently Levine et a ${ }^{22}$ reported two cases of migraine with lupus anticoagulant. These patients did not have SLE at the time of assessment. In a review of the literature these authors identified six other cases of migraine occurring in patients with lupus anticoagulant in addition to the cases noted above. They suggest that alteration of platelet membrane phospholipids due to LAC or possibly interaction of LAC with neuronal phospholipid may be responsible for migraine in these patients.

We have recently recognized a group of young patients who presented with histories of migraine and/or neurological deficits (transient or prolonged) who were found to have either LAC or ACA or both. In only a few of these patients were other major risk factors for stroke identified and only one patient has gone on to develop features consistent with SLE. It is the purpose of this paper to present our initial experience with LAC and to suggest a possible association with migraine.

\section{Methods}

We reviewed the records of 15 patients seen by the neurology service at Kingston General Hospital who were found to have lupus anticoagulant and/or anticardiolipin antibodies. Twelve of these patients presented since July 1986. In the other three patients LAC had been recognized several years earlier.

The LAC was detected by two methods. Initial screening was done with an activated partial thromboplastin time test (APTT reagent - Actin FS, American Dade). Presence of the LAC was confirmed using Exner's Kaolin clotting time method. ${ }^{23}$

Cardiolipin antibodies were measured by a modification of the ELISA method described by Koike et al. ${ }^{24}$ Results were expressed in arbitrary units (AU) where one AU is 1 standard deviation above the mean for the normal control population (50 normal subjects). Values for the IgM and IgG ACA in excess of $3 \mathrm{AU}$ were regarded as positive.

Migraine is a clinical diagnosis and the features of this disorder have been well documented. $25,26,27,28$ In this study patients were diagnosed as having classical migraine, common migraine, complicated migraine or basilar artery migraine. Classical migraine referred to a typical migrainous headache following a brief transient neurological deficit while common migraine was not associated with a neurological deficit. In complicated migraine the neurological deficit persisted during and after the headache. The features of basilar artery migraine have been described by Bickerstaff. ${ }^{28}$

Neurological symptoms and signs were considered to be transient if resolution occurred within 24 hours.

\section{RESULTS}

The clinical and laboratory data of all 15 patients are summarized in Tables 1 and 2. Twelve of the patients $(80 \%)$ were female. The average age at the time of diagnosis of LAC was 29.4 years (19 to 49) for females and 35 years for males. A history of migraine was identified in 10 of the 15 patients in this study.

Six patients were initially referred to the neurology service for assessment of headache and migraine was diagnosed in five (cases 1,6,8,9,10). Two of these patients (cases 8,9), who had histories of recurrent thrombotic complications and spontaneous abortions, had already been identified as having LAC but their migraine problem had not been assessed. The remaining patient (case 15) had non-migrainous headache.

Three patients (cases 2,3,4,) developed neurological deficits acutely and a diagnosis of complicated migraine was made after initial investigations failed to identify other possible etiologies for their symptoms and signs. One of these patients (case 3 ) was recognized to have a long history of common migraine and reported increased severity of headaches in the 6 months prior to her presentation.

One patient (case 5) presented with an acute cerebral ischemic event and was found to have had recent onset of classical migraine. Two other patients (cases 11,13 ) presented with acute focal neurological deficits and CT head scan evidence of infarcts but did not have a migraine history. Two patients (cases 12,14 ) presented with fluctuating sensory symptoms and no history of migraine. The final patient (case 7) presented with a four week history of gradually developing hemichoreoathetosis and a 15 month history of migraine. Within the following month she developed sufficient features to establish a diagnosis of SLE.

Seven patients were identified as having ischemic stroke. Four of these cases $(1,2,3,5)$ were from the migraine group. Major risk factors for stroke (apart from antiphospholipid antibodies) were identified in two patients; one was hypertensive (case 13), and the other had diffuse narrowing of the left internal carotid artery on angiography (case 5). No other vascular abnormalities were detected in the stroke group of patients.

The birth control pill (BCP) was used by seven patients, six of them being in the migraine group. Two of the patients with stroke were using the BCP (cases 2,5).

Three female patients (cases 1,6,8) had one or more spontaneous abortions which are a recognized complication of LAC. 3 Two patients (cases 8,9 ) had experienced considerable morbidity secondary to the thrombotic tendency caused by LAC.

LAC was identified in 12 patients. The three patients negative for LAC (cases 10,11,14) showed evidence of elevated ACA levels. Elevated ACA levels were present in a total of 11 patients. Other serology included the VDRL which was positive in only one case (15). Positive ANA titres were seen in a total of five patients. Three of the migraine group had positive ANA titres including the one patient that has developed SLE (case 7).

\section{Discussion}

A total of $10 \mathrm{LAC}$ cases with migraine have been reported in the literature. ${ }^{22}$ In our group of 15 patients with LAC migraine was diagnosed in 10. In 7 of these patients migraine was either an acute presenting problem (cases 2,4 ), had developed over the 
Table 1: Clinical Features and Treatment in 15 Patients with LAC or ACA and Neurologic Symptoms

\begin{tabular}{|c|c|c|c|c|c|c|c|c|}
\hline $\begin{array}{l}\text { Age at } \\
\text { Presen- } \\
\text { tation } \\
\text { Sex } \\
\text { Case } \\
\text { No. Age S }\end{array}$ & $\begin{array}{l}\text { Presenting Symptoms } \\
\text { and Signs }\end{array}$ & $\begin{array}{l}\text { Headache } \\
\text { History }\end{array}$ & $\begin{array}{l}\text { Headache } \\
\text { Desig- } \\
\text { nation }\end{array}$ & $\begin{array}{l}\text { Arterial } \\
\text { or } \\
\text { Venous } \\
\text { Throm- } \\
\text { boses }\end{array}$ & $\begin{array}{l}\text { Sponta- } \\
\text { neous } \\
\text { Abortions }\end{array}$ & $\begin{array}{l}\text { BCP } \\
\text { Use }\end{array}$ & Fatigue & $\begin{array}{l}\text { Treatment } \\
\text { and Course }\end{array}$ \\
\hline
\end{tabular}

1. 24 F Right arm paresis, dysarthria, vertigo, and unsteady gait resolving over

Throbbing headache preceded by scintillating sco- migraine toma and recurring for 8 weeks. Also occurred 5 years earlier

2. 25 F Right visual field scotoma, expressive dysphasia and right hemiparesis, resolving over several hours, followed by throbbing headache

3. $31 \mathrm{~F}$ Generalized headaches followed by right arm hemiparesis, blurred vision, drowsiness and speech problems all resolving in several hours

4. $47 \mathrm{~F}$ Generalized throbbing headache preceded by blurred vision, dizziness, left side paresthesia and loss of consciousness

5. $25 \mathrm{~F}$ Transient loss of consciousness, right hemiparesis, aphasia, resolving over several days

6. $21 \mathrm{~F}$ Frequent (several/day) recurrent headaches with dizziness and diploplia

7. $21 \mathrm{~F}$ Left arm paresis

Left hemichoreoathetosis

8. 25 F Recurrent transient visual loss, memory loss with mild headaches

9. $38 \quad \mathrm{M}$ Peripheral vascular insufficiency

Recurrence of presenting problem

Mild headache monthly since starting $\mathrm{BCP}$ one year earlier

Recurrent throbbing headaches with nausea, photophobia since age 14

No other headache history

Throbbing headache occasionally preceded by scintillating scotoma, recurring for four months

Same as presenting problem

Headaches improved after BCP use stopped

Recurrent headaches preceded by scotoma for 15 months

Recurrent right sided headaches preceded by scintillating scotoma for 10 years

Headaches preceded by scintillating scotoma for 10 years

Recurrent headaches preceded by scintillating scotoma (since childhood) or right arm numbness (for 2 years)

11. 35 M Loss of balance, dysarthria, left hemiparesis, transient vertigo and diploplia

12. 19 F Transient left arm numbness

13. $35 M$ Dysphasia resolving over one week

14. $32 \mathrm{~F}$ Fluctuating symptoms of bilateral visual impairment, small right inferior field defect and "altered sensation" in right arm

15. 49 F Recurrent right sided head pain since removal of a right sphenopalatine connective tissue mass one year earlier

No headache history

No headache history
Ill defined pressure

sensation
No other headache history none classical no no yes yes Diltiazem, propranolol ineffecand com- no tive. ASA helped for two

plc.

migraine months. LTAC controlled recurrence of neurological deficits but headaches continue

common no no no no ASA ineffective

and com-

LTAC prevented recurrence of

plc.

migraine

complc.

migraine neurological deficits

$\begin{array}{lllll}\begin{array}{l}\text { classical no no } \\ \text { migraine }\end{array} & \text { yes no } \begin{array}{l}\text { Neurological deficit recurred } \\ \text { and partially resolved over } \\ \text { several months }\end{array}\end{array}$

basilar no yes X1 yes no ASA - stable

artery

migraine

classical no no yes yes

migraine

classical

migraine

DVT $\mathrm{X} 3$ yes $\mathrm{X} 4$ no occ.

classical DVT $x 2 \quad \mathrm{n} / \mathrm{a}$

migraine arterial

occlu-

sion $\mathrm{X} 1$

Classical no no yes no

migraine

n/a no

Trihexyphenidyl ineffective

Choreoathetosis improved when steroids started for presumed CNS involvement with SLE

none

no

n/a

n/a no

ASA with partial improvement

none

no no

yes no

n/a no

no no

BCP stopped, no recurrence

ASA - Stable

No treatment at this time

none

no

no

no

no

no

no

Prednisone started and headache eased and CT evidence of reduction in size of remaining connective tissue mass

DVT - deep venous thrombosis

LTAC - long term anticoagulation with coumadin

SLE - systemic lupus erythematosus 


\section{Table 2. Laboratory Findings in Study Patients}

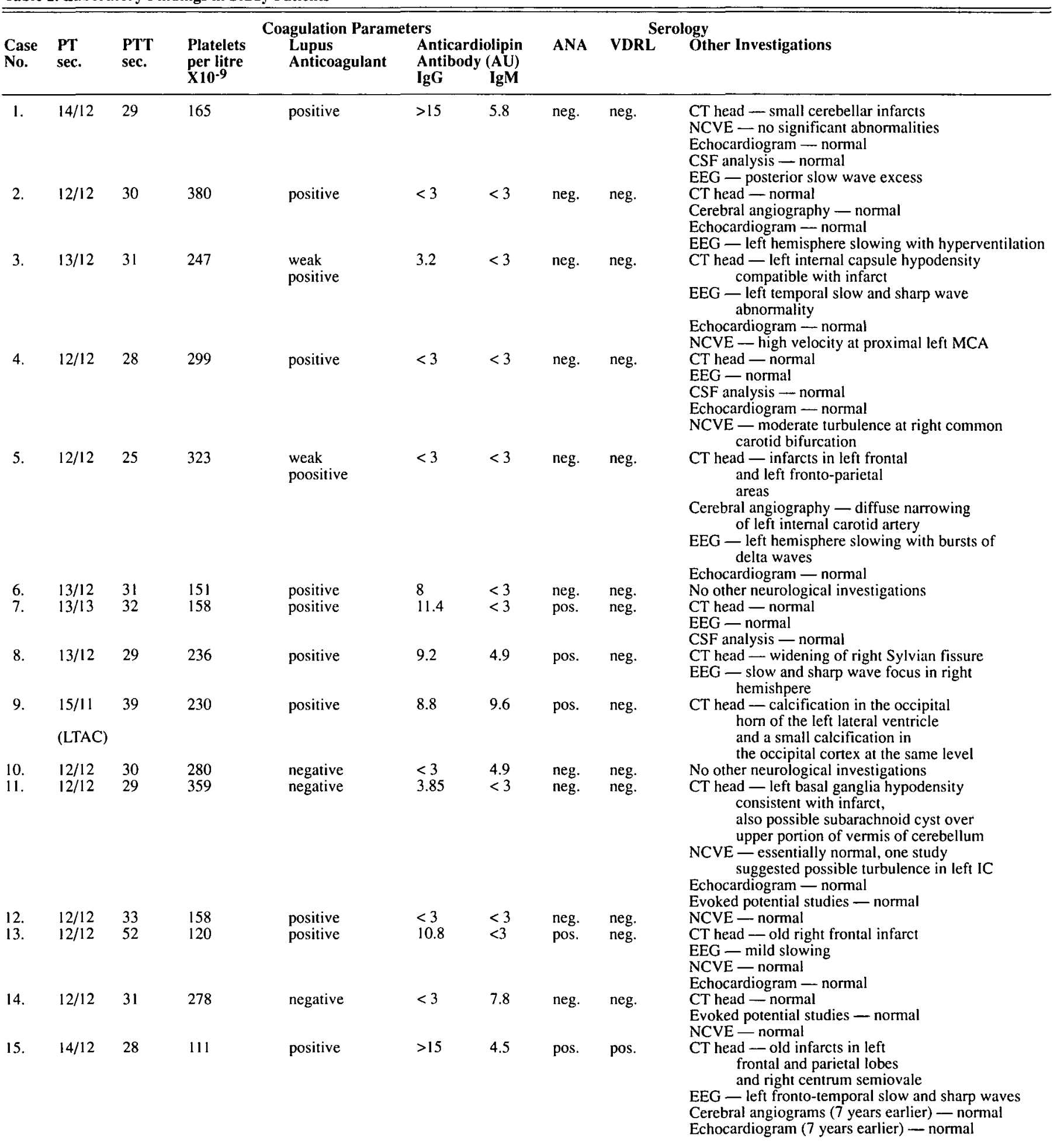

$\begin{array}{llll}\text { Abbreviations: } & \text { ANA - antinuclear antibody } & \text { LTAC - long term anticoagulation } & \text { neg. - negative } \\ & \text { CSF - cerebrospinal fluid } & \text { with coumadin } & \text { pos. - positive } \\ & \text { CT - computerized tomography } & \text { NCVE - non-invasive cerebrovascular } & \text { PT - prothrombin time } \\ & \text { EEG - electroencephalogram } & \text { examination } & \text { PTT - partial thromboplastin time } \\ & & \text { (Doppler flow studies) } & \text { VDRL - venereal diseases research laboratory test }\end{array}$


preceding 15 months (cases $5,6,7$ ) or was a long standing problem that had become more severe in the preceding year (cases 1,3 ). In the remaining three patients (cases $8,9,10$ ) there was a long unchanging history of migraine. None of the patients in the migraine group suffered from common migraine alone. All of the migraine sufferers had experienced either transient or more prolonged neurological symptoms and signs.

It is possible that several of our cases $(2,3,4)$ who were diagnosed as complicated migraine may have simply suffered from TIA or stroke with an accompanying headache. However the gradual progression of neurological deficits observed in case 2 is much more typical of classical migraine than stroke. Case 3 had clearly suffered from worsening headaches typical of common migraine prior to her presentation. Only case 4 had no previous headache history.

Our group of migraine patients represents a selected population. Four of the 10 patients had suffered an ischemic stroke at a relatively young age. Vascular abnormalities were only identified in one of these patients (case 5). Three of our nine female migraine patients had one or more spontaneous abortions. Two patients had previously suffered deep venous thromboses and one patient developed SLE. However, it must be noted that apart from a tendency for thrombotic complications eight of our ten migraine patients with LAC were otherwise well. It is of interest to also note that three of our patients without other underlying disease reported feeling generally fatigued and that this eased considerably when therapy with ASA was instituted.

The birth control pill was used by 7 of our 12 female patients but without a control population we are unable to comment on any possible significance of this finding.

There was not an absolute correlation between LAC and elevated ACA levels in our patients. This has been recently report$\mathrm{ed}^{29}$ and suggests that we may be looking at a range of antibodies with overlapping activity rather than a single antibody against a specific epitope. In our three ACA positive - LAC negative patients no thrombotic complications or stroke were documented. Otherwise no differences between our LAC negative and LAC positive patients was recognized.

Only two patients had prolonged partial thromboplastin times (PTT). Twelve patients however were positive for LAC using the kaolin clotting time (KCT). This can be explained by the relative insensitivity of the PTT reagent used (Dade Actin FS) to the effects of LAC. Therefore if LAC is suspected clinically a more sensitive test such as the KCT should be performed.

At this time the prevalence of migraine in the population of patients with antiphospholipid antibodies is not known. We also do not know the prevalence of these antibodies in the normal population or the population that attends neurology clinics. Therefore, even in our cases where there had been a recent change in migraine status, we do not know if the association with lupus anticoagulant was merely coincidental or if migraine patients with LAC represent some subgroup of the migraine population with a specific, as yet unknown, pathophysiology. However this data raises the question of a possible association between LAC and migraine and further investigation into this problem is warranted.

\section{REFERENCES}

1. Conley CL, Hartmann RC. A hemorrhagic disorder caused by circulating anticoagulant in patients with disseminated lupus erythematosus. Clin Invest 1952; 31:621-622.

2. Espinoza LR, Hartmann RC. Significance of the lupus anticoagulant. Am J Hematol 1986; 22: 331-337.

3. Rapaport SI, Feinstein DI. Lupus anticoagulant and other hemostatic problems. In: Wallace DJ, Dubois EL, eds. Lupus Erythematosus, 3rd Ed. Lea and Febiger 1987: 27I-280.

4. Schleider MA, Nachman RL, Jaffe EA, et al. A clinical study of the lupus anticoagulant. Blood 1976; 48: 499-509.

5. Gastineau DA, Kazmier FJ, Nichols WL, et al. Lupus anticoagulant: An analysis of the clinical and laboratory features of 219 cases. Am J Hematol 1985; 19: 265-275.

6. Bowie EJW, Thompson JH, Cascuzzi PA, et al. Thrombosis in SLE despite circulation anticoagulants. J Lab Clin Med 1963; 62: 416-430.

7. Elias M, Eldor A. Thromboembolism in patients with the "Lupus" - type circulating anticoagulant. Arch Intern Med 1984; 144: 510-515.

8. Mueh JR, Herbst KD, Rapaport SI. Thrombosis in patients with the lupus anticoagulant. Ann Intern Med 1980; 92: 156-159.

9. Boey ML, Colaco CB, Gharavi AE, et al. Thrombosis in systemic lupus erythematosus: Striking association with the presence of circulating anticoagulant. Br Med J 1983; 287: 1021-1023.

10. Glueck HI, Kant KS, Weiss MA, et al. Thrombosis in systemic lupus erythematosus. Relation to the presence of circulating anticoagulants. Arch Intern Med 1985; 145: 1389-1395.

11. Harris EN, Gharavi AE, Boey ML, et al. Anticardiolipin antibodies: Detection by radioimmunoassay and association with throbosis in systemic lupus erythematosus. Lancet 1983; 2: 12111214.

12. Colaco CB, Male DK. Anti-phospholipid antibodies in syphilis and a thrombotic subset of SLE: Distinct profiles of epitope specificity. Clin Exp Immunol 1985; 59: 449-456.

13. Carreras LO, Defreyn G, Machin SJ, et al. Arterial thrombosis, intrauterine death and "lupus" anticoagulant: Detection of immunoglobulin interfering with prostacyclin formation. Lancet 1981; 1: 244-246.

14. Fisher M, McGehee W. Cerebral infarct, TIA, and lupus inhibitor. Neurology 1986; 36: 1234-1237.

15. Landi G, Calloni MV, Sabbadini MG. Recurrent ischemic attacks in two young adults with lupus anticoagulant. Stroke 1983; 14: $377-379$.

16. Kelly RE, Gilman PB, Kovacs AG. Cerebral ischemia in the presence of lupus anticoagulant. Arch Neurol 1984; $41: 521-523$.

17. D'Alton JG, Preston DN, Bormanis J, et al. Multiple transient ischemic attacks, lupus anticoagulant and verrucous endocarditis. Stroke 1985; 16: 512-514.

18. Baker WH, Potthoff WP, Biller J, et al. Carotid artery thrombosis associated with lupus anticoagulant. Surgery $1985 ; 8: 612-615$.

19. Tabachnick-Schor NF, Lipton SA. Association of lupus like anticoagulant and nonvasculitic cerebral infarction. Arch Neurol 1986; 43: $851-852$

20. Levine SR, Welch KMA. Cerebrovascular ischemia associated with lupus anticoagulant. Stroke 1987; 18: 257-263.

21. Brandt KD, Lessell S. Migrainous phenomena in systemic lupus erythematosus. Arthritis Rheum 1978; 21: 7-16.

22. Levine SR, Joseph R, D'Andrea G, et al. Migraine and the lupus anticoagulant. Case reports and review of the literature. Cephalalgia 1987; 7: 93-99.

23. Exner T, Rickard KA, Kronenberg $H$. A sensitive test demonstrating lupus anticoagulant and its behavioral patterns. $\mathrm{Br} \mathrm{J}$ Haematol 1978; 40: 143-151.

24. Koike T, Sueshi M, Funaki H, et al. Anti-phospholipid antibodies and biological false positive serological test for syphilis in patients with systemic lupus erythematosus. Clin Exp Immunol 1984; 56: 193-199. 
25. Rose FC. Headache: Definitions and Classification. In: Rose FC, ed. Handbook of Clinical Neurology, Vol. 4: Headache. Elsevier Science Publishers 1986; 48: 1-12.

26. Ad Hoc Committee on Classification of Headache. Classification of headache. JAMA 1962; 179: 127-128.

27. Ziegler DK. The headache symptom. How many entities? Arch Neurol 1985; 42: 273-274.
28. Bickerstaff ER. Basilar artery migraine. Lancet 1961; 1: 15-17.

29. Meyer O, Piette J, Bourgeois P, et al. Anti-phospholipid antibodies: A disease marker in 25 patients with antinuclear antibody negative systemic lupus erythematosus. Comparison with a group of 91 patients with antinuclear antibody positive systemic lupus. J Rheumatol 1987; 14: 502-506. 